\title{
Tatalaksana Perioperatif pada Pasien dengan Cardiac Implantable Electronic Devices (Cieds) atau Alat Elektronik Kardiovaskular Implan (Aleka)
}

\section{Perioperative Management in Patients with Cardiac Implantable Electronic Devices}

\author{
Cindy Elfira Boom ${ }^{\bowtie}$, Ornella Widyapuspita \\ SMF Anestesi dan Perawatan Intensif Pascabedah, Rumah Sakit Jantung Nasional Harapan \\ Kita, Jakarta, Indonesia \\ ${ }^{\circledR}$ Korespondensi: cindynugroho@yahoo.com
}

\begin{abstract}
The number of patients using cardiac implantable electronic devices (CIEDs) has continued to grow at an astounding rate over the year throughout the world, but there are still many anesthesiologists who are not comfortable in managing perioperative service in these patients due to lack of knowledge and experience in device programming. Cardiac implantable electronic device is a term that includes the use of a pacemaker for bradyarrhythmias and implantable cardioverter defibrillator (ICD) for tachyarrhythmias, as well as cardiac resynchronization therapy (CRT) for diastolic dysfunction with conduction delays. Until now, there were at least more than 250,000 adults and children undergoing pacemaker implantation each year, therefore, it is important for an anesthesiologist to understand and be able to plan a perioperative management with multidisciplinary team in order to reduce morbidity and mortality of these patients. This literature review was created to provide information about CIEDs, focusing on perioperative management, and providing a management algorithms which can be implemented in everyday practice.
\end{abstract}

Keywords: cardiac implantable electronic devices; implantable cardioverter defibrilator; pacemaker; perioperative management

\begin{abstract}
ABSTRAK
Jumlah pasien pengguna cardiac implantable electronic devices (CIEDs) atau alat elektronik kardiovaskular implan (ALEKA) hingga saat ini makin bertambah setiap tahunnya di penjuru dunia, namun masih banyak ahli anestesi yang belum nyaman dalam mengelola pelayanan perioperatif pada pasien-pasien tersebut dikarenakan kurangnya pengetahuan dan pengalaman pemrograman alat untuk menatalaksana pasien. Alat elektronik kardiovaskular implan merupakan sebuah istilah yang mencakup penggunaan alat pacu jantung untuk bradiaritmia dan implantable cardioverter defibrilator (ICD)/
\end{abstract}


defibrilator kadioverter implan (DKI) untuk takiaritmia, serta cardiac resynchronization therapy (CRT)/ terapi resinkronisasi jantung (TRJ) untuk disfungsi diastolik dengan hambatan konduksi. Hingga saat ini, tercatat setidaknya lebih dari 250.000 pasien dewasa maupun anak menjalani pemasangan alat pacu jantung tiap tahunnya, oleh karena itu, penting bagi seorang dokter anestesi untuk memahami dan mampu membuat perencanaan perioperatif dengan tim multidisiplin agar dapat menurunkan morbiditas dan mortalitas pasien. Tinjauan pustaka ini dibuat untuk memberikan info seputar ALEKA dengan berfokus pada manajemen perioperatif pasien dengan ALEKA, serta algoritma tatalaksana yang dapat diimplementasikan dalam praktik sehari-hari.

Kata Kunci: alat pacu jantung; ALEKA; defibrilator kardioverter implan; tatalaksana perioperatif

\section{PENDAHULUAN}

Jumlah pasien pengguna cardiac implantable electronic devices (CIEDs) atau bisa disebut alat elektronik kardiovaskular implan (ALEKA) hingga saat ini makin bertambah setiap tahunnya di seluruh dunia, namun masih banyak ahli anestesi yang belum nyaman dalam mengelola pelayanan perioperatif pada pasien-pasien tersebut dikarenakan kurangnya pengetahuan, pengalaman dan alat pemrogram untuk menatalaksana pasien. Pada banyak pusat kesehatan, penggunaan magnet telah menjadi pendekatan standar pada pasien-pasien dengan CIEDs. Namun, walau penggunaan ini sesuai untuk banyak kasus, penggunaan magnet secara 'buta' sebagai strategi manajemen tidaklah lebih dari sekedar rasa aman palsu, karena masih ada risiko kegagalan mengidentifikasi masalah perioperatif, mencapai tujuan operasi, atau keduanya. 1

Hingga saat ini, tercatat setidaknya terdapat lebih dari 200 model pacemaker/alat pacu jantung yang diproduksi oleh 27 perusahaan, dan lebih dari 250.000 pasien dewasa maupun anak menjalani pemasangan alat pacu jantung tiap tahunnya. Referensi kepustakaan yang tertinggal atau terbatasnya pelatihan seringkali menyebabkan kebingungan dalam perawatan perioperatif pasien-pasien tersebut. $^{2}$

ASA bersama Heart Rhythm Society (HRS) telah mempublikasikan sebuah rekomendasi internasional mengenai tatalaksana perioperatif pasien dengan ALEKA pada tahun 2011. Pada versi revisi ini, rekomendasi tatalaksana pasien dengan ALEKA masih sama dengan publikasi tahun 2005, namun pada versi revisi lebih ditekankan pada manajemen dengan pendekatan individual, komunikasi efektif multidisiplin sebelum prosedur, serta pendekatan tim selama periode perioperatif. ${ }^{1}$

\section{KLASIFIKASI ALEKA/ CIEDS}

Alat elektronik kardiovaskular implan merupakan sebuah istilah yang mencakup penggunaan alat pacu jantung untuk bradiaritmia dan defibrilator kadioverter implan (DKI) untuk takiaritmia, serta cardiac resynchronization therapy/ terapi resinkronisasi jantung (CRT) untuk disfungsi diastolik dengan hambatan konduksi. $^{3}$ 
Alat Pacu Jantung

Alat pacu jantung/ pacemaker merupakan salah satu modalitas perawatan aritmia jantung, terutama bradiaritmia, yang paling dapat dipercaya sejak tahun 1950. Sistim awalnya berupa alat pacu jantung asinkron dengan sebuah kabel-pacu, yang memacu jantung pada kecepatan tetap. Seiring berkembangnya jaman, maka teknologi alat pacu jantung makin berkembang dan penggunaannya dapat disesuaikan dengan kebutuhan tiap individu pasien. ${ }^{4}$

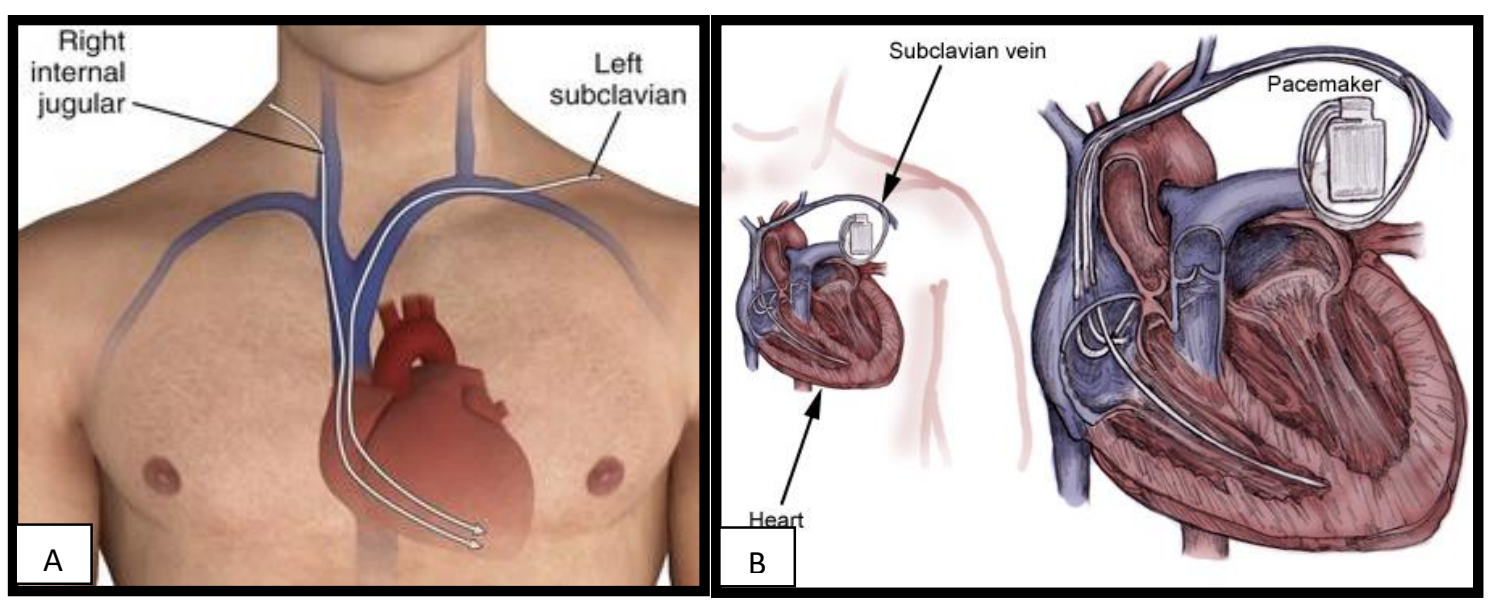

Gambar 1. (A) Pilihan jalur pemasangan pacu jantung intravena; (B) Lokasi kabel-pacu intrakardiak. ${ }^{5,6}$

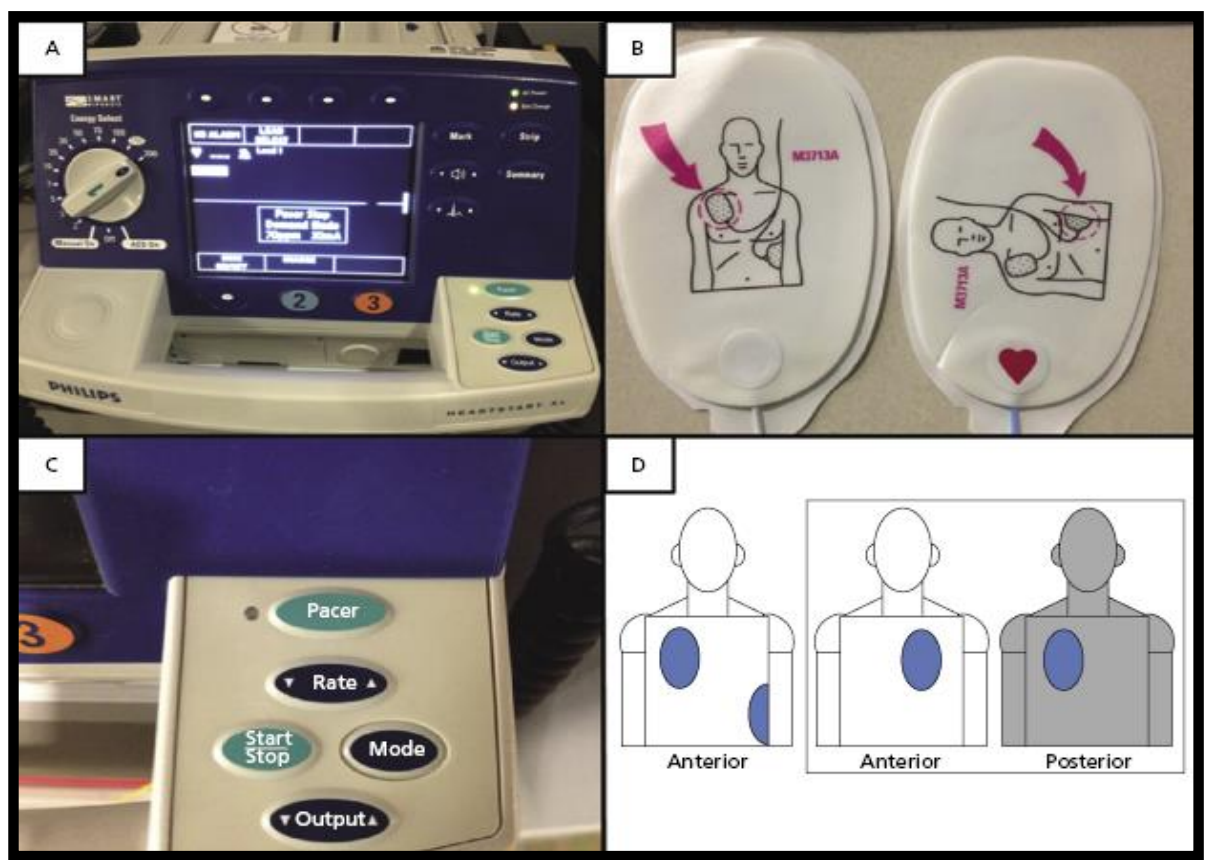

Gambar 2. Lokasi pemasangan dan alat pacu jantung transkutan ${ }^{7}$ 
Kabel-pacu bisa bersifat unipolar, bipolar atau multipolar. Kabel-pacu umumnya diletakkan di appendage atrium kanan, ventrikel kanan (RV), atau pada tipe alat 2 ruang, pada keduanya. Pada kabel-pacu bipolar, kedua anoda dan katoda berada pada kabel-pacu yang sama, sedangkan pada model unipolar, generator pulsasi bertindak sebagai anoda, dan kabel-pacu sebagai katoda. Model bipolar lebih banyak digunakan karena lebih tahan terhadap gangguan elektromagnetik/ electromagnetic interference (EMI). ${ }^{1,8}$

\section{Indikasi Pemasangan Alat Pacu Jantung}

Alat pacu jantung dapat dipasang secara permanen maupun sementara, dan indikasi pemasangannya pun makin berkembang. Alat ini dapat digunakan melalui beberapa cara, mulai dari pemakaian lempeng eksternal, pemasangan darurat kabel-pacu lewat akses vena sentral/ central vein catheter (CVC), hingga pemasangan kabel-pacu permanen intrakardiak bersama generator pulsasi. Alat pacu jantung umumnya diindikasikan untuk gangguan pembentukan impuls dan gangguan konduksi jantung. ${ }^{1}$

Berikut adalah daftar indikasi pemasangan alat pacu jantung berdasarkan pedoman yang dibuat oleh HRS tahun 2008: ${ }^{9}$

1. Bradikardia karena sinus node dysfunction/ disfungsi nodus sinus (SND) dan atrioventricular node dysfunction/ disfungsi nodus atrioventrikular (AND)
a. SND: sinus bradikardia simtomatik yang persisten dan inkompetensi kronotropik tanpa sebab jelas
b. Blok AV didapat pada dewasa

c. Blok AV derajat 3 atau derajat 2 atas pada level anatomi manapun yang terkait dengan:

- Bradikardia simtomatik/ aritmia ventricular dengan presumsi disebabkan oleh blok AV

- Kondisi medis lain yang memerlukan terapi berefek bradikardia simptomatik

- Pasien sinus ritme bebas gejala dengan periode asistol terdokumentasi $\geq 3 \mathrm{~s}$, escape rate $<40$ denyut/ menit atau escape rhythm dibawah nodus AV

- Pasien AF bebas gejala dengan bradikardia dengan periode tunda $\geq 1$ dan minimal $\geq 5 \mathrm{~s}$

- Setelah ablasi AV junction terkait dengan AV blok postoperatif yang diperkirakan tidak bisa diatasi setelah operasi jantung

- Terkait dengan penyakit neuromuskular dengan blok AV

d. Blok AV derajat 2 yang terkait dengan bradikardia simptomatik tanpa memperdulikan lokasi blok

e. Blok AV derajat 3 persisten pada level anatomi manapun dengan kecepatan ventrikel $\geq 40$ denyut per menit jika terdapat kardiomegali atau disfungsi ventrikel kiri (LV), atau jika lokasi blok berada di bawah nodus AV

f. Blok AV derajat 2-3 saat latihan, tanpa iskemi miokard

2. Blok bifasik kronis

3. Pacu jantung untuk blok AV yang terkait dengan infark miokard

4. Sindroma sinus karotis hipersensitif dan sinkop neurokardiogenik 
5. Pascatransplantasi jantung

6. Pencegahan dan terminasi aritmia dengan pacu jantung

7. Kardiomiopati hipertrofi

8. Anak, remaja dan pasien dengan penyakit jantung bawaan (PJB)

\section{Mode dan Kode Alat Pacu Jantung}

Untuk mengerti lebih jelas mengenai bahasa alat pacu jantung, perlu dipahami adanya sistim kode yang dikembangkan dan dipublikasi oleh aliansi North American Society of Pacing and Electrophysiology/ British Pacing and Electrophysiology Group (NASPE/ BPEG). Sistim kode ini berisi sistim 5 posisi dengan sebuah huruf di tiap posisi untuk menggambarkan fungsi program antibradikardia, denyut adaptif dan pemacuan multi lokasi. Posisi pertama mengindikasikan ruang yang dipacu, posisi kedua mengindikasikan ruang yang ditilik, posisi ketiga menggambarkan respon terhadap tilikan. Posisi keempat dan kelima mendeskripsikan fungsi yang dapat diprogram dan fungsi antitakiaritmia, namun keduanya jarang digunakan. ${ }^{4,8}$

Pada zaman dahulu, pemrograman alat pacu jantung dilakukan oleh konsultan ahli, menggunakan programer dari produsen alat, namun sekarang penggunaan magnet lebih disukai karena mudah dan dapat digunakan untuk mengamankan alat sambil membuat mode asinkron jika diperlukan pada implan produksi tahun 2000 dan setelahnya. Ringkasan mengenai kode ini dapat dilihat pada Tabel 1. ${ }^{1}$

Tabel 1. Kode generik program alat pacu jantung ${ }^{1}$

\begin{tabular}{lllll}
\hline \multicolumn{1}{c}{ I. Ruang pacu } & \multicolumn{1}{c}{ II. Tilikan } & \multicolumn{1}{c}{$\begin{array}{c}\text { III. Respon } \\
\text { terhadap tilikan }\end{array}$} & $\begin{array}{c}\text { IV. Modulasi } \\
\text { kecepatan }\end{array}$ & $\begin{array}{c}\text { V. Pacing multi } \\
\text { lokasi }\end{array}$ \\
\hline $\mathrm{A}=$ Atrium & $\mathrm{A}=$ Atrium & $\mathrm{I}=$ Inhibisi & $\mathrm{R}=$ Modulasi & $\mathrm{A}=$ Atrium \\
$\mathrm{V}=$ Ventrikel & $\mathrm{V}=$ Ventrikel & $\mathrm{T}=$ Trigger $/$ picu & $\mathrm{O}=$ none & $\mathrm{V}=$ Ventrikel \\
$\mathrm{D}=$ Dual & $\mathrm{D}=$ Dual & $\mathrm{D}=(\mathrm{I}$ dan $/$ atau & & $\mathrm{D}=$ Dual \\
$(\mathrm{A} \& \mathrm{~V})$ & $(\mathrm{A} \& \mathrm{~V})$ & $\mathrm{T})$ & $(\mathrm{A} \& \mathrm{~V})$ \\
& $\mathrm{O}=$ none & $\mathrm{O}=$ none & & $\mathrm{O}=$ none \\
\hline
\end{tabular}

Catatan: ${ }^{9}$

Kode dual pada alat pacu jantung berarti alat menyediakan sinkronisasi atrioventrikular (AV), dimana pemacuan atrial akan terjadi dalam mode terinhibisi dan alat pacu akan memastikan hal tersebut diikuti dengan kejadian ventrikular normal.

Kode inhibisi berarti ruangan di pacu terus, kecuali terdeteksi aktivitas elektrik intrinsik selama interval pemacuan.

Kode trigger berarti alat pacu hanya mengeluarkan pulsasi sebagai respon dari tilikan aktivitas jantung. 


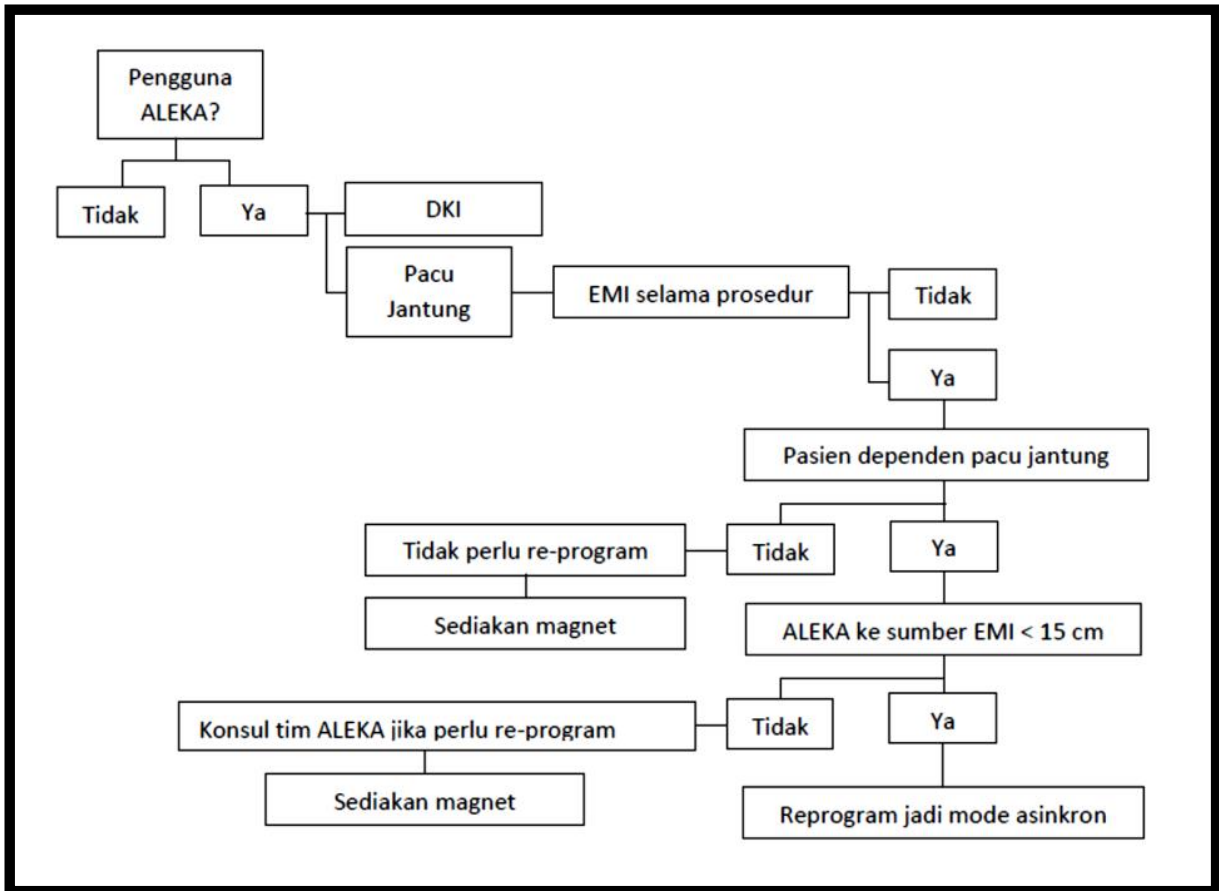

Gambar 3. Algoritma pasien dengan ALEKA yang akan menjalani suatu prosedur/ tindakan. ${ }^{8}$

Defibrilator Kardioverter Implan (DKI)/ Implantable Cardioverter Defibrilator (ICD)

Defibrilator kardioverter implan adalah alat yang mampu mendeteksi aritmia ventrikel dan menghantarkan defibrilasi saat diperlukan. Generasi saat ini menggunakan generator pulsasi yang ditanamkan pada kantung pektoral subkutan, dan mampu mengatasi sekitar $98 \%$ episode fibrilasi ventrikel (VF). ${ }^{8}$

Pada mulanya, DKI digunakan hanya untuk mencegah kematian jantung mendadak akibat takikardia ventrikular (VT) atau fibrilasi ventrikel (VF) pada pasien risiko tinggi yang berhasil selamat dari satu kali atau lebih tindakan resusitasi. Hal ini dikenal sebagai Pencegahan Sekunder. Data di Pusat Jantung Nasional Harapan Kita (PJNHK) menunjukkan peningkatan jumlah pasien yang dilakukan implantasi DKI untuk pencegahan sekunder pada 3 tahun terakhir sebesar $30 \%$ per tahun. Bagaimanapun, angka ini belum mencakup semua pasien yang selayaknya mendapat DKI. Di Pusat Jantung Nasional Harapan Kita, pada tahun 2012 saja, terdapat 97 kejadian henti jantung saat perawatan, dan 62 (64\%) diantaranya meninggal dunia. Pada tahun 2013, angka kejadian henti jantung adalah 93 kasus, hanya 25 kasus (26\%) yang selamat. ${ }^{12}$

Syok yang dihasilkan oleh DKI dapat mengakibatkan gangguan tangkapan pascasyok sementara pada alat pacu jantung karena paparan miokard terhadap aliran listrik densitas tinggi, oleh karena itu, disarankan kepada pengguna DKI untuk melakukan evaluasi rutin tiap 3 bulan dan tiap paparan terhadap EMI. ${ }^{9}$ 


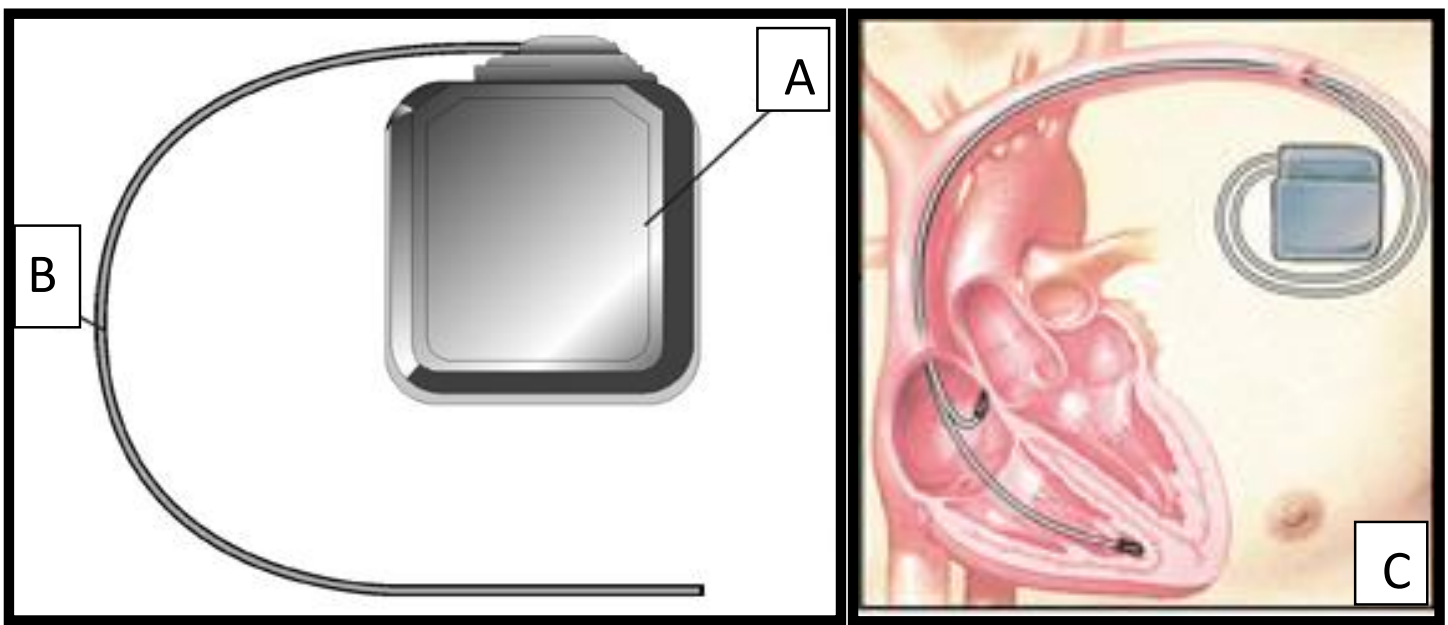

Gambar 4. Defibrilator kardioverter implan ${ }^{10,11}$

Keterangan: (A) Generator pulsasi, berisi baterai dan sirkuit komputer kecil; (B) Kabel-pacu, yang mengirim impuls dari generator pulsasi ke otot jantung, serta menilik aktivitas listrik jantung;(C) posisi DKI saat dipasang di jantung

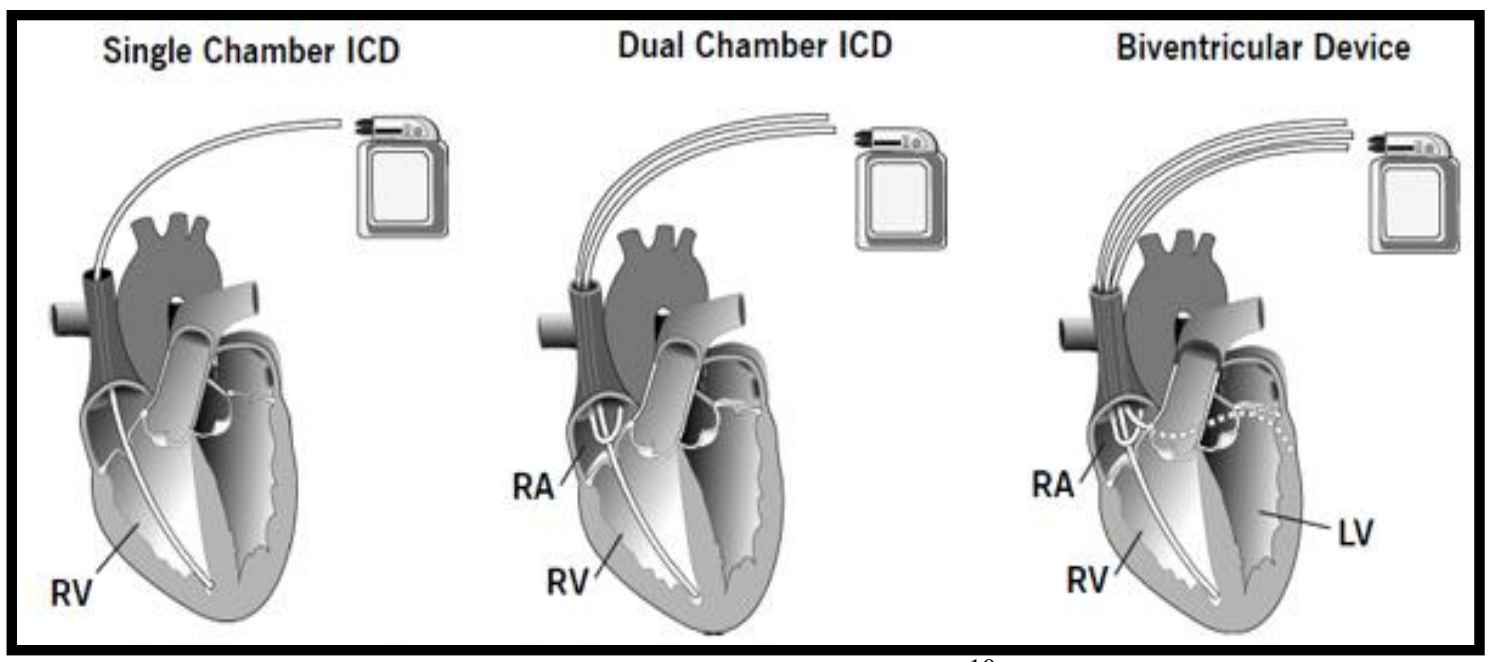

Gambar 5. Jenis-jenis DKI ${ }^{10}$

Keterangan gambar: DKI ruang tunggal: kabel-pacu terpasang pada ventrikel kanan. Jika diperlukan, energi dihantarkan ke ventrikel untuk membantu kontraksi normal. DKI ruang ganda: kabel-pacu dipasang pada atrium kanan dan ventrikel kanan. Energi dihantarkan ke atrium kanan terlebih dahulu lalu ke ventrikel kanan, membantu jantung berdenyut sesuai urutan normal. Alat biventrikular: 2-3 kabel-pacu diletakkan pada atrium kanan, ventrikel kanan, dan ventrikel kiri melalui vena sinus koroner. Alat ini membantu jantung berdenyut dengan lebih seimbang dan secara spesifik dipergunakan pada pasien dengan gagal jantung. 


\section{Mode dan Kode DKI}

Terdapat sistim kode 4 posisi dari NASPE/ BPEG untuk DKI. Posisi pertama mendeskripsikan ruang mana yang diberikan syok (A-atrial, Vventrikel, O- tidak ada, D-dual/ ganda); posisi kedua menunjukkan posisi pemacuan antiaritmia diberikan (juga dengan kode $\mathrm{A}, \mathrm{V}, \mathrm{O}, \mathrm{D})$; posisi ketiga menunjukkan mekanisme deteksi takiaritmia, dengan elektrokardiogram (E) atau rerata hemodinamik $(\mathrm{H})$; posisi keempat adalah 3-5 huruf kode kapabilitas pemacuan dari alat tersebut. Dari penjelasan tersebut, maka dapat disimpulkan bahwa DKI dapat memiliki kode program seperti VOH-VVIR. ${ }^{8}$

Tabel 2. Kode generik program $\mathrm{DKI}^{13}$

\begin{tabular}{llll}
\hline \multicolumn{1}{c}{ I. Syok } & \multicolumn{1}{c}{$\begin{array}{c}\text { II. Pemacuan } \\
\text { antitakiaritmia }\end{array}$} & III. Deteksi takikardia & \multicolumn{1}{c}{$\begin{array}{c}\text { IV. Pemacuan } \\
\text { antibradikardia }\end{array}$} \\
\hline $\mathrm{A}=$ Atrium & $\mathrm{A}=$ Atrium & $\mathrm{E}=$ Elektrokardiogram & $\mathrm{A}=$ Atrium \\
$\mathrm{V}=$ Ventrikel & $\mathrm{V}=$ Ventrikel & $\mathrm{H}=$ Hemodinamik & $\mathrm{V}=$ Ventrikel \\
$\mathrm{D}=$ Dual $(\mathrm{A} \& \mathrm{~V})$ & $\mathrm{D}=$ Dual $(\mathrm{A} \& \mathrm{~V})$ & & $\mathrm{D}=$ Dual $(\mathrm{A} \& \mathrm{~V})$ \\
$\mathrm{O}=$ none & $\mathrm{O}=$ none & & $\mathrm{O}=$ none \\
\hline
\end{tabular}

\section{Indikasi}

Pada awalnya, DKI digunakan pada kasus-kasus VT atau VF, namun saat ini, semua pasien dengan kardiomiopati signifikan fraksi ejeksi (EF) $\leq 35 \%$ adalah kandidat untuk pemasangan DKI. 1,2

Indikasi pemasangan DKI antara lain: ${ }^{2}$

1. Takikardia ventrikel

2. Fibrilasi ventrikel

3. Pasien pasca-MI dengan EF $\leq$ 30\% (MADIT II)

4. Kardiomiopati karena sebab apapun dengan $\mathrm{EF} \leq 35 \%$ (SCDHeFT)

5. Kardiomiopati hipertrofik

6. Menunggu transplantasi jantung

7. Sindroma Q-T memanjang

8. Displasia ventrikel kanan aritmogenik

9. Sindroma Brugada (RBBB, ST elevasi di V1-V3)

\section{EVALUASI PRAOPERATIF}

Pengenalan ALEKA sebelum operasi penting untuk diketahui oleh dokter bedah dan anestesi. Tipe ALEKA yang digunakan dapat diketahui melalui anamnesa, rekam medik pasien, kartu informasi ALEKA, dan foto rontgen dada. Setelah mengidentifikasi adanya penggunaan ALEKA, penting untuk melibatkan seorang kardiologis, sebagai bentuk pendekatan multidisiplin manajemen ALEKA yang turut mendukung luaran pasien lebih baik. ALEKA idealnya telah diperiksa dalam 6 bulan terakhir untuk menentukan beban pemacuan, agar dapat memastikan parameter kabel-pacu dan fungsi alat optimal. Pasien dengan beban pemacuan $\geq 40 \%$ atau memiliki ritme dominan pemacuan pada EKG dianggap dependen pada alat pacu jantung. ${ }^{14}$

Fokus evaluasi praoperatif pasien dengan ALEKA antara lain 1) menentukan apakah pasien menggunakan ALEKA; 2) menentukan tipe alat yang digunakan; 3) menentukan apakah pasien bergantung pada pemacuan anti bradikardia; 4) menentukan fungsi alat. ${ }^{8,13}$

Manuver provokatif untuk memicu bradikardia dengan manuver Valsava memanjang atau dengan pemberian esmolol/ adenosin dosis rendah, dapat membantu memastikan tilikan, pemacuan, dan tangkapan mekanik. 
Namun tidak direkomendasikan, dan harus dilakukan dengan sangat hati-hati. 4,8

Perlu diperhatikan beberapa hal yang perlu dipersiapkan sebelum operasi, yaitu: $:^{1,8,13}$

1. Menentukan apakah gangguan elektromagnet akan terjadi selama prosedur

2. Menentukan apakah diperlukan pemrograman ulang praoperatif dari fungsi pemacuan ALEKA menjadi mode asinkron atau menonaktifkan semua fungsi khusus termasuk fungsi adaptasi denyut
3. Menunda fungsi antiaritmia, jika ada

4. Menyarankan penggunaan elektrokauter pada operator

5. Evaluasi kemungkinan pengaruh/ interaksi teknik anestesi yang digunakan terhadap fungsi ALEKA

Hal-hal yang perlu dicegah dalam periode perioperatif antara lain: (1) kerusakan pada alat, kabel-pacu, atau lokasi implantasi; (2) kegagalan hantaran syok atau pemacuan; (3) perubahan pada pola pemacuan; (4) hantaran pemacuan atau syok tidak sesuai kondisi. ${ }^{8}$

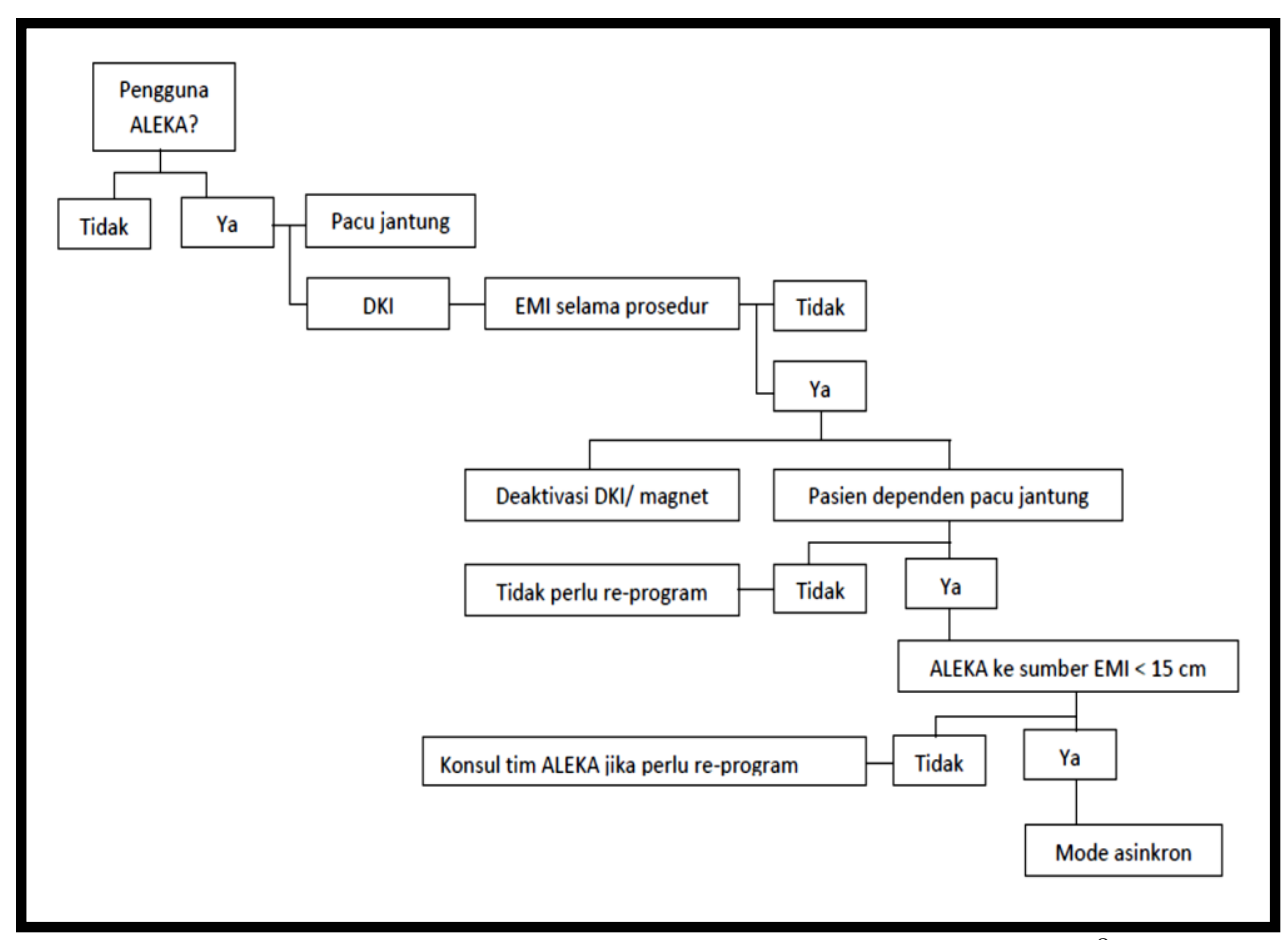

Gambar 6. Algoritma manajemen pasien dengan $\mathrm{DKI}^{8}$ 


\section{Gangguan Alat Pacu Jantung}

Gangguan alat pacu jantung pada umumnya memiliki 3 etiologi utama, yaitu: (1) gangguan tangkapan; (2) gangguan kabel-pacu; atau (3) gangguan generator. Gangguan tangkapan dapat terjadi karena iskemi/ infark miokard, gangguan keseimbangan asam basa, gangguan elektrolit, atau level obat anti aritmia abnormal. Gangguan kabel-pacu dan generator jarang terjadi. ${ }^{2}$

\section{GANGGUAN}

\section{ELEKTROMAGNETIK/ELECTRO} MAGNETIC INTERFERENCE (EMI)

Periode perioperatif kadang kala menjadi periode bermasalah bagi pasien dengan ALEKA karena pasien terpapar dengan banyak sumber energi yang dapat menyebabkan EMI dan berinteraksi dengan ALEKA. Interaksi ini menimbulkan berbagai efek, seperti inhibisi pemacuan, kerusakan pada permukaan ujung kabel-pacu dengan jaringan, kerusakan generator pulsasi, dan gangguan algoritme respon denyut yang menyebabkan pemacuan terlalu cepat. ${ }^{1,15}$

\section{Defibrilasi}

Sebelum melakukan defibrilasi atau kardioversi pada pasien dengan ALEKA dan terapi menggunakan magnet, seluruh sumber EMI harus dihilangkan dan magnet dilepaskan untuk melanjutkan terapi antiaritmia. Jika muncul aritmia yang mengancam nyawa, gunakan pedoman ACLS untuk level energi dan penempatan paddle. Jika memungkinkan, coba minimalisir aliran listrik yang melewati generator dan kabel-pacu dengan: (1) memposisikan pad sejauh mungkin dari generator dan kabel-pacu; (2) memposisikan pad tegak lurus terhadap aksis mayor dari generator dan kabel-pacu dengan menempatkannya pada posisi anteriorposterior. ${ }^{13}$

\section{Litotripsi}

Literatur yang ada belum dapat menyediakan informasi yang cukup mengenai manajemen pasien pengguna ALEKA yang menjalani radioterapi. Komentar dari pihak ASA dan HRS juga masih terpecah mengenai apakah radioterapi dikontraindikasikan pada pasien-pasien dengan ALEKA. ${ }^{13}$

Pada prosedur ini sebaiknya dilakukan evaluasi alat pacu jantung dan DKI dalam 1 bulan sebelum prosedur. Litotripsi dikatakan dapat menginduksi gangguan tilikan dan menekan pemacuan. Hindari sinar yang terfokus ke generator. Jika sistim litotripsi memicu gelombang $\mathrm{R}$, pemacuan atrial sebaiknya dihentikan sementara sebelum prosedur dimulai. 13,16

\section{Terapi elektrokonvulsif (ECT)}

Belum ada penelitian yang mendukung teori bahwa ECT menyebabkan kerusakan permanen pada ALEKA. Jika ECT harus dilakukan, sebaiknya konsultasikan terlebih dahulu dengan dokter yang memberi instruksi dan kardiolog untuk perencanaan prosedur ECT awal dan lanjutan. Seluruh pasien harus menjalani interogasi ALEKA secara komperhensif sebelum prosedur. ALEKA dinonaktifkan selama prosedur, namun pada pasien dependen alat pacu jantung, mungkin diperlukan pemacuan sementara untuk mempertahankan irama dan denyut jantung selama prosedur. ${ }^{13}$

\section{Magnetic Resonance Imaging (MRI)}

Beberapa komponen elektromagnetik pada MRI dapat menyebabkan induksi elektrik atau termal pada implan kabelpacu. Induksi aliran listrik dapat menginisiasi aritmia atau menyebabkan kabel-pacu mendapatkan tilikan yang 
rendah atau berlebihan, dan berpotensi fatal. Sebagai tambahan, karena jaringan dekat ujung kabel-pacu memiliki konduktifitas terbatas, maka energi akan diubah menjadi panas pada lokasi ini, sehingga mnyebabkan pembentukan jaringan parut dan edema. Medan magnet dalam MRI juga memiliki efek yang tidak dapat diprediksi terhadap aktivitas reed switch pada DKI, sebagai tambahan. Perubahan gradien magnetik yang terlalu cepat dapat diregistrasi sebagai aritmia mengancam nyawa, dan mengakibatkan DKI merespon dengan melepaskan pemacuan anti takikardia atau bahkan syok/ kejut listrik. Beberapa kasus kematian pernah dilaporkan akibat kejadian ini. ${ }^{15,17}$

ALEKA tipe $M R$-conditional (diketahui memiliki bahaya pada lingkungan MR spesifik dengan kondisi penggunaan spesifik) telah dibuat dengan komponen yang dikembangkan secara khusus dan telah diuji aman untuk penggunaan pada lingkungan MR. Perubahan-perubahan tersebut mengurangi risiko komplikasi seperti pemanasan ujung kabel-pacu, pengaturan stimulasi bipolar, serta penempatan filter spesifik untuk mencegah alat mendeteksi sinyal eksternal non-kardiak. ${ }^{17}$

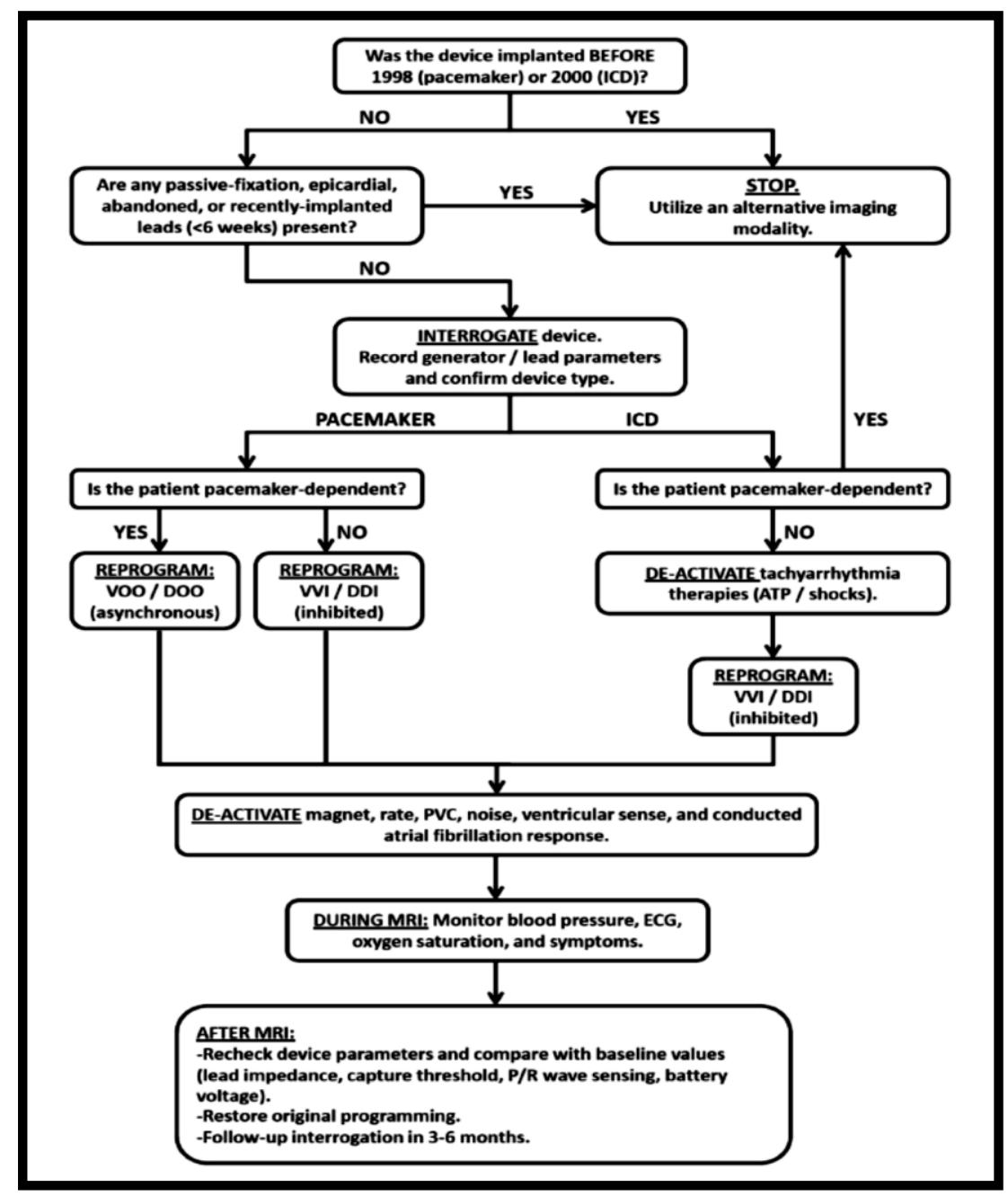

Gambar 7. Algoritma protokol Hopkins untuk penggunaan MRI pada pasien dengan ALEKA $^{15}$ 
$\mathrm{DDI}=$ dual-chamber inhibited pacing without atrial tracking; $\mathrm{DOO}=$ dual-chamber asynchronous pacing; $\mathrm{ECG}=$ electrocardiography; $\mathrm{ICD}=$ implantable cardioverter defibrillator; $\mathrm{MRI}=$ magnetic resonance imaging $; \mathrm{PVC}=$ premature ventricular contraction; $\mathrm{VOO}=$ ventricular asynchronous pacing; $\mathrm{VVI}=$ ventricular inhibited pacing .

\section{Transurethral Needle Ablation (TUNA)/ Transurethral Resection of The Prostate (TURP) \\ Prosedur TUNA dan TURP} menggunakan energi radiofrekuensi dan electrosurgery dalam manajemen penyakit prostat. Belum ada laporan bahwa TURP dapat menginhibisi aktivitas alat pacu jantung pada alat dengan sistim modern, sehingga tidak diperlukan interogasi alat peri-prosedur. ${ }^{13}$ Untuk prosedur yang menggunakan elektrokauter, konsensus

\begin{abstract}
ASA dan HRS menyarankan untuk: (1) memposisikan lempeng aliran kembali agar aliran listrik tidak melewati generator pulsasi maupun kabel-pacu dari ALEKA; (2) hindari area listrik dari kauter mendekati generator atau kabelpacu (termasuk tidak melambaikan kauter di atas generator); (3) gunakan aliran pendek, intermiten dan ireguler pada level energi paling rendah; (4) gunakan kauter bipolar atau ultrasonik (harmonik) jika memungkinkan. ${ }^{13}$
\end{abstract}

Tabel 3. Rekomendasi untuk minimalisasi EMI periode perioperatif. ${ }^{18}$

\section{Elektrokauter}

1. Maksimalkan jarak antara monopolar dengan ALEKA, pertimbangkan penggunaan bipolar jika perlu dekat ALEKA

2. Gunakan pengaturan kekuatan minimum yang adekuat

3. Untuk monopolar, letakkan elektroda balik pada tempat sejauh mungkin dari ALEKA. Seringkali, tungkai atas kontralateral menjadi pilihan lokasi terbaik.

4. Untuk prosedur di bawah umbilikus, seringkali tidak diperlukan prosedur khusus

5. Prosedur di atas umbilikus lebih sering mengalami EMI, dan pemrograman ulang atau penggunaan magnet mungkin diperlukan, terutama jika pasien dependen terhadap ALEKA

6. Batasi penggunaan kauter menjadi short burst (1 detik burst kauter tiap 10 detik) jika terlihat ada inhibisi

7. Pantau seksama pasien dengan pletisimografi atau tekanan arterial

8. Setelah prosedur, segera evaluasi adanya perubahan baik pada perangkat lunak ALEKA MRI (versi ESC)

1. Pasien dibagi menjadi 3 kelompok berdasarkan risko. Pasien dependen pacu jantung (risiko sangat tinggi), pasien dengan DKI (risiko tinggi), pasien non-dependen pacu jantung (risiko rendah)

2. Medan kekuatan $<1,5 \mathrm{~T}$; specific absorption rate $(\mathrm{SAR})>2 \mathrm{~W} / \mathrm{kg}$

3. Interogasi ALEKA; atur ulang menjadi mode asinkron untuk pasien dependen pacu jantung; deaktivasi terapi takikardia pada DKI, program menjadi tilikan bipolar; deaktivasi algoritme khusus (adaptasi kecepatan denyut)

4. Monitor dengan pulse oksimetri, siapkan troli darurat, siapkan staf bersertifikat ACLS dan programer ALEKA

5. Reinterogasi ALEKA dan lakukan pengaturan ulang ke parameter awal jika diperlukan pada 1 minggu dan 3 bulan pasca-prosedur 


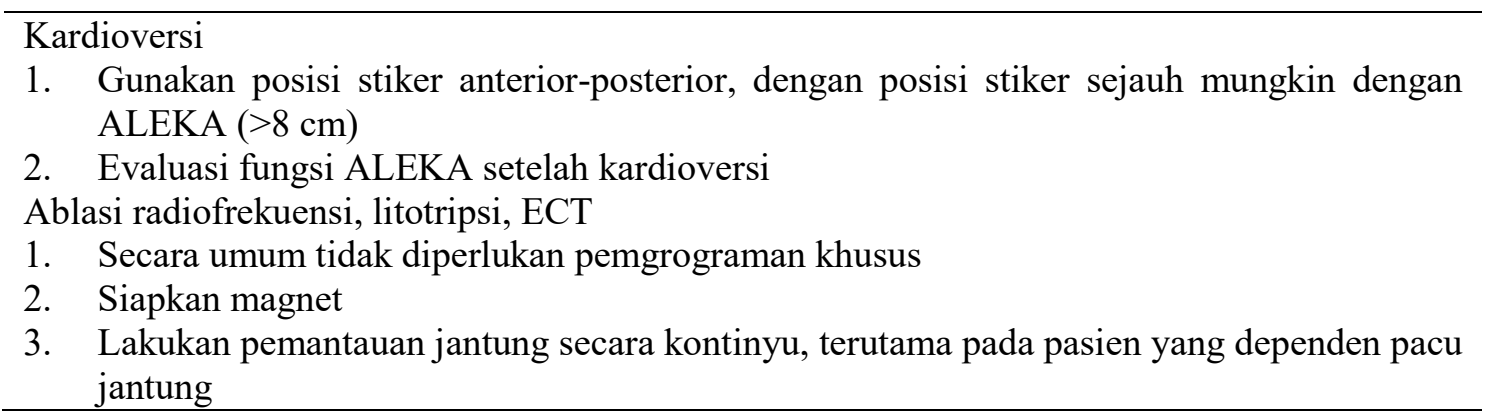

\section{Agen Anestesi dan ALEKA}

Teknik anestesi yang digunakan disesuaikan dengan kebutuhan pasien. Agen narkotik dan inhalasi dapat digunakan dengan baik, karena agenagen tersebut tidak mengganggu ambang aliran dan voltase dari alat pacu jantung, namun perlu disarankan untuk tidak menggunakan nitrous oxide (NO) pada pasien dengan alat pacu jantung yang baru dipasang, karena dapat menyebabkan ekspansi gas dalam kantung tempat implantasi, mengakibatkan hilangnya kontak anoda dan malfungsi sistim pacu. Penggunaan halotan dapat menurunkan interval QT. ${ }^{4,19}$

Agen anestesi yang umum digunakan dipercaya tidak mempengaruhi ambang pemacuan. Hiperventilasi (yang dapat menurunkan konsentrasi kalium serum secara drastis), gangguan asam-basa, elektrolit, pemberian cairan, transfusi darah, iskemi miokardial, dan konsentrasi anestesi lokal dalam darah yang signifikan dapat meningkatkan ambang tangkapan dari kabel-pacu dan dapat mengubah impedansi kabel-pacu. ${ }^{1}$

Induksi anestesi menggunakan suksinilkolin dapat menyebabkan fasikulasi otot yang akan menginhibisi komplit alat pacu jantung karena tilikan berlebihan yang menyebabkan henti jantung pada pasien dependen pacu jantung. Fasikulasi otot ini dapat dihindari dengan penggunaan pelumpuh otot non-depolarisasi sebelum pemberian suksinilkolin. Komplikasi ini juga dapat dihindari dengan memprogram alat pacu jantung menjadi mode asinkron. Hindari pula penggunaan etomidat dan ketamin karena efek mioklonus yang dihasilkan. ${ }^{4,9}$

\section{Pertimbangan Intraoperatif}

Aktivitas utama terkait manajemen ALEKA intraoperatif melingkupi: ${ }^{8}$

1. Pemantauan fungsi alat-alat

2. Pencegahan potensi disfungsi ALEKA

3. Melakukan defibrilasi atau kardioversi darurat, atau topangan denyut jantung selama prosedur

Pemantauan intraoperatif meliputi EKG kontinu dan pulsasi perifer dengan palpasi, auskultasi, pemantauan tekanan arteri, USG pulsasi perifer, pletisimografi pulsasi atau oksimetri. Walau tidak ada penelitian mengenai penggunaan EKG kontinu intraoperatif, beberapa laporan kasus menyatakan pentingnya penggunaan alat tersebut dalam mendeteksi disfungsi jantung atau alat pacu jantung yang digunakan. Pihak ASA merekomendasikan penggunaan EKG kontinu sejak mulai anestesi hingga pasien dipindahkan keluar ruang pemulihan. Semua pemantauan ini berlaku untuk pasien dengan anestesi regional maupun umum. ${ }^{1,4,9}$ 
Perlu diperhatikan bahwa jika akan melakukan pemasangan kateter vena sentral (CVC) dengan kawat pemandu pada pasien dengan DKI, harus sangat berhati-hati agar tidak terjadi kontak antara kawat pemandu dengan elektroda pendeteksi, karena dapat mengaktivasi terapi anti takikardia. ${ }^{16}$

Saat terjadi perubahan aktivitas elektrik atau kondisi hemodinamik labil mendadak yang terkesan berkaitan dengan EMI harus mengingatkan operator untuk berhenti menggunakan kauter sementara hingga kondisi hemodinamik stabil kembali. DKI yang telah di-deaktivasi oleh magnet dapat direaktivasi cepat dengan pelepasan magnet. ${ }^{1}$

\section{Pertimbangan Pasca-Operatif}

Manajemen pasca-operatif dari pasien dengan ALEKA utamanya meliputi interogasi dan pemulihan fungsi ALEKA di ruang pemulihan atau di ruang perawatan intensif. Lakukan pemantauan kecepatan denyut dan irama, pastikan alat bantu pemacuan dan defibrilasi siap selama periode postoperatif. ${ }^{13}$

Denyut dan ritme jantung harus dipantau secara kontinyu selama periode pascaoperatif. Fasilitas pemacuan cadangan dan peralatan kardioversi harus siap sedia. Salah satu aspek kontroversial dalam perawatan pasca-operatif adalah perlunya interogasi kesesuaian pada pengaturan semuaALEKA sebelum pasien dipindahkan dari ruang pemulihan ke ruang perawatan intensif, atau lingkungan tanpa pemantauan. Walau tidak didiskusikan secara spesifik, pemeriksaan fungsi alat mungkin diperlukan dalam beberapa kondisi, seperti adanya pemasangan kateter arteri pulmonal setelah implantasi kabel-pacu (< 6 minggu), atau terjadi pemasangan kanula di jantung untuk penggunaan alat pintas jantung paru atau bantuan sirkulasi mekanis lain. ${ }^{1}$

\section{RINGKASAN}

Penilaian dan manajemen pada pasien dengan ALEKA memerlukan perhatian khusus. Pemahaman yang adekuat mengenai indikasi pemasangan, mode yang tersedia, dan program dari tiap jenis ALEKA, serta pendekatan individual pasien merupakan kunci utama bagi pasien dengan ALEKA dalam menjalani prosedur bedah dan non-bedah yang aman.

Manajemen perioperatif ideal untuk pasien dengan ALEKA dilakukan berdasarkan pendekatan multidisiplin. Seorang spesialis anestesi harus familiar dengan rekomendasi yang paling baru serta implementasinya di lapangan. Walau perkembangan tekonologi ALEKA dan peralatan operasi telah mengurangi kejadian EMI dalam beberapa tahun terakhir, namun keselamatan pasien tetap harus menjadi fokus utama pelayanan. Rekomendasi praktik terbaru menekankan adanya pendekatan pada kebutuhan individual tiap pasien, dengan tindakan spesifik untuk meminimalkan paparan ALEKA terhadap EMI dan melindungi pasien dari perubahan hemodinamik yang tidak diinginkan.

\section{DAFTAR PUSTAKA}

1. Stone EM, Salter B, Fischer A. Perioperative management of patients with cardiac plantable electronic devices. Br J Anaesth. 2011: p. i16-26

2. Rozner MA. Perioperative care of the patient with a cardiac pacemaker or ICD. Rev Mex Anestesiol. 2009: p. S190-97 
3. Neelankavil JP, Thompson A, Mahajan A. Managing cardiovascular implantable electronic devices (CIEDs) during perioperative care. APSF Newsletter. 2013

4. Rastogi S, Goel S, Tempe DK, Virmani S. Anaesthetic management of patients with cardiac pacemakers and defibrillators for noncardiac surgery. Ann Card Anaesth. 2005; 8: p. 21-32

5. Lynch CA. A dangerous diagnosis in an asymptomatic patients: case quiz. medscape.com.

[Online]; 2016 [cited 2017 March 30

6. Berman ES. Emergency cardiac pacing. In Roberts JR, Hedges JR, editors. Clinical Procedures in Emergency Medicine. California: Saunders/Elsevier; 2010

7. Bunch J, Osborn JS, Day JD. Temporary cardiac pacing. Thoracic Key; 2016 [cited 2017 March 30

8. Nair SG. Anaesthetic management of patients with pacemakers and implantable cardioverter defibrillator. In South Zone Anaesthesia Conference (CASCO); 2012; Coimbatore. p. 1-15

9. Rapsang AG, Bhattacharyya P. Pacemaker and implantable cardioverter defibrilators-general and anesthetic considerations. Rev Bras Anestesiol. 2014; 64(3): p. 2015-14

10. Staff MC. Heart arrhytmia. Mayo Clinic. [Online]; 2016 [cited 2017 March 31. Available from: http://www.mayoclinic.org/diseases -conditions/heartarrhythmia/diagnosistreatment/treatment/txc-20188390

11. Staff CC. Implantable cardioverter defibrillator (ICD). Cleveland Clinic. [Online].; 2015 [cited 2017
March 31. Available from: http://my.clevelandclinic.org/health /articles/implantable-cardioverterdefibrillator-icd

12. Hanafy DA, Rahadian A, Tondas AE, Hartono B, Tanubudi D, Munawar M, et al. Pedoman terapi memakai alat elektronik kardiovaskular implan (Aleka). 1st ed. Jakarta: Centra Communications; 2014

13. American Society of Anaesthesiologists Task Force on Perioperative Management of Patients with Cardiac Rhythm Management Devices. Practice advisory for the perioperative management of patients with cardiac rhythm management devices: pacemakers and implantable cardioverter-defibrillators.

Anesthesiology. 2011; 114(2): p. 247-61

14. Chia PL, Foo D. A practical approach to perioperative management of cardiac implantable electronic devices. Singapore Med J. 2015; 56(10): p. 538-41

15. Chow GV, Nazarian S. Magnetic resonance imaging for patients with cardiac implantable electrical devices. Cardiol Clin. 2014; 32(2): p. 299-304

16. Crossley GH, Poole JE, Rozner MA, Asirvatham SJ, Cheng A, Chung MK, et al. The heart rhythm society (HRS)/ american society of anesthesiologist (ASA) expert consensus statement on the perioperative management of patients with implantable defibrillators, pacemakers and arrhythmia monitors: facilities and patient management. Heart Rhythm. 2010; 8(7): p. 1114-34

17. Van der Graaf AWM, Bhagirath $P$, Gotte MJW. MRI and cardiac implantable electronic devices; 
current status and required safety conditions. Neth Heart J. 2014; 22: p. 267-76

18. Misiri J, Kusumoto F, Goldschlager $\mathrm{N}$. Electromagnetic interference and implanted cardiac devices: the medical environment (part II). Clin Cardiol. 2012; 35(6): p. 321-28
19. Pervez MR. Pcaemakers \& implantable cardioverterdefibrillators (ICDs)- part 1 . Anesthesia tutorial of the week (ATOTW). [Online].; 2013 [cited 2017 March 31. Available from: https://www.aagbi.org/sites/default/ files/299\%20Pacemakers\%20and\% 20ICDs\%20Part\%201.pdf 